\title{
Baking Value of Wheat-Fonio Flour Composites
}

\author{
Ivan Švec, Marie Hrušková \\ Department of Carbohydrate Chemistry and Technology, University of Chemistry and Technology Prague, \\ Czech Republic \\ Email: Ivan.Svec@vscht.cz
}

\begin{abstract}
Three different addition levels of commercial fonio flour (2.5, 5.0, 10.0\%) were mixed with wheat flour to explore flour pasting, dough rheological behaviour and bread quality. During farinograph test, fonio flour addition clearly shortened wheat dough stability (from 12.0 up to 3.5 min). Extensigraph data were influenced equivocally. Viscosity profiles determined by using of Amylograph and Rapid Visco Analyser, corresponded together (peak viscosities 2263 (control), 2348, 2367, $2381 \mathrm{mPa} \cdot \mathrm{s}$ ). During fermentograph, maturograph and oven-spring tests, composite dough variants exhibited higher dough volumes $(+20 \%$ in average). Bread volume has risen by $2.5 \%$ fonio flour dosage only (from 337 to $402 \mathrm{ml} / 100 \mathrm{~g}$ ); specific volumes of more enhanced variants were comparable to control. Crumb penetration corresponded to specific bread volume, rising from 12.6 $\mathrm{mm}$ to $22.3 \mathrm{~mm}$. Fonio wholemeal did not affected bread sensory profiles. Principal component analysis pointed to higher baking potential of wheat-fonio composite 95:5.
\end{abstract}

Keywords: Wheat flour composite; fonio flour; rheological properties; composite bread quality; Principal Component Analysis

\section{Introduction}

Fonio (Digitaria spp.) belongs to cereals of Sahel region of the Africa, and its breeding is dated to 5,000 years BC. Fonio is classified among grasses (Poaceae) and into the same subfamily as maize, sorghum and millet. In nature, fonio species fruiting white (D. exilis Stapf.) and black coloured seeds (D. iburu Stapf.) could be found. Domestic names are 'acha' and 'iburu', respectively, and especially the former type is commercialized in Guinea, Mali and Nigeria. In further countries as Senegal and Sierra Leone, mainly iburu is produced $[1,2]$. In Togo and Benin, fonio is either the staple or the major part of the $\operatorname{diet}(2 / 3$ of daily food consumption [3]).

Comparing white and black variant, composition of fonio seeds is similar and close to wheat one - the main constituent are polysaccharides $(75 \%)$, followed by proteins (8-10\%) and fat (1\%). Tiny seeds allow producing wholegrain flour only, similarly to case of teff or chia. Within wholegrain flours from white and black grains, differences are also negligible ([4]; Table 1). Fonio is a good source of calcium and phosphorus [5]. Local culinary custom covers preparation of fonio couscous or ingera, flat spongy type of fermented wholegrain bread.

Table 1. Average nutrition composition of fonio seeds (Coda et al., 2010)

\begin{tabular}{llllllll}
\hline \multirow{2}{*}{ Fonio type } & \multicolumn{7}{c}{ Constituent (\%) } \\
& Moisture & Saccharides & Proteins & Fat & Dietary fibre & Minerals & Phenolics \\
\hline \multirow{2}{*}{ acha } & 16.8 & 73.9 & 7.4 & 1.8 & 0.5 & 0.5 & 1.9 \\
iburu & 9.5 & 78.0 & 7.9 & 2.0 & 0.5 & 0.5 & 5.4 \\
\hline
\end{tabular}

Fonio flour has a potential to be used in baking industry to manufacture biscuits [6] or bread. Bread recipes could be generally wheat-less [7-9], or the fonio flour replaces part of wheat [10-12]. Proteins in fonio, especially in acha, alpha-like prolamins with similar size:charge ratio to the alpha-gliadins in durum wheat[13]. During a fermentation process, granules of fonio starch are damaged gradually Edema et al. [14] mentioned a partial expansion of polygonal starch granules, and releasing of some starch granules from the granules as a result of microorganism enzymes action. Those changes 
contribute to the increase in water absorption and dough elasticity. A more effective capturing of fermentation gases led to improvement in crumb porosity and texture of leavened baked goods [14]. Fonio flour could be also used as raw material in multi-composite flour blends, e.g. wheat-fonio-cowpea one, examined for bread and cookie manufacturing $[15,16]$.

The aim of the presented work is to describe effect of three addition levels of fonio flour on properties of wheat flour, using internal complex model of technological quality assessment. The model includes basic analytics, rheological testing of non-fermented and fermented dough and baking trial with leavened bread as the final product. Multivariate data statistical treatment should point to connexion among evaluated features and their contribution to quality of leavened bread as a final product.

\section{Materials and Methods}

\subsection{Materials}

Wheat flour (WF) as a base of flour composites was produced by the Czech commercial mill Delta Prague (harvest 2015), and it is characterised by average technological quality (protein content 13.0\%, Zeleny value $32 \mathrm{ml}$, Falling Number $400 \mathrm{~s}$ ). Commercial product "Farine de fonio" (i.e. fonio flour, abbreviation FF, production year 2015) was delivered by the French company Gaia (Graulhet, France). A fonio seed as raw material was imported from Burkina Faso, West Africa. Proximate chemical composition was declared by producer on commercial package (proteins $8.0 \%$, saccharides $84.0 \%$, fat $1.8 \%$ ), which corresponds with data published by Coda et al. 2010 (Table 1). In addition, contents of insoluble/soluble dietary fibre fractions as well as total dietary fibre one were determined for both wheat and fonio flour (IDF 2.30\% and 3.45\%. SDF $1.20 \%$ and $1.31 \%$. TDF $3.40 \%$ and $5.22 \%$, respectively).

\section{$2.2 \quad$ Analytical Methods}

Basic technological behaviour of all composite samples is expressed by Zeleny sedimentation value (protein quality) and Falling Number (estimation of - amylases activity and rate of damaged starch), following the internationally approved norms.

\subsection{Rheology Testing of Non-fermented Dough}

Changes in non-fermented dough properties were recorded by using the Farinograph and the Extensigraph apparatuses (Brabender GmbH., Duisburg, Germany; norms ISO 5530-1 and ISO 5530-2, respectively). The extensigraph test was conducted in a shortened version, i.e. in terms of 30 and 60 min of dough resting. For sufficient description of extensigraph curves, only elasticity-to-extensibility ratio together with extensigraph energy could be extracted, thus these main parameters are discussed later.

\subsection{Viscous Behaviour of Flour Composites}

Pasting properties were explored by using of the Amylograph Brabender (ICC standard No. 126/1) and the Rapid Visco Analyser (Perten Instruments, Sweden; ICC standard No. 162). Employing of both apparatuses is aimed at comparison of results gained according to traditional and modern method. For this purpose, only temperatures of gelatinization beginning (pasting temperature) and viscosity maximum (peak viscosity) as the representatives are considered.

\subsection{Rheology Behaviour of Fermented Dough}

Following internal procedures, behaviour of leavened dough was observed within three technological phases of fermentation process [17]. The first one is called fermentation and dough volume changes are recorded on the Fermentograph SJA (Sweden). The second one is called proofing, during which dough rheological behaviour is recorded on the Maturograph Brabender. The last one is the first stage of baking, assessed by using of the Oven-spring recorder (Brabender, Germany; abbreviation OTG). 


\subsection{Baking Trial}

Laboratory baking trial and consecutive evaluation of bread quality including sensory profile were performed according to internal methods, too, and the process is depicted in previous articles [18, 19]. Shortly, full-formula bread dough consisted of $300.0 \mathrm{~g}$ (composite) flour, $12.0 \mathrm{~g}$ yeast, $5.1 \mathrm{~g}$ salt, $4.5 \mathrm{~g}$ sugar, 3.0 g margarine Perla (39\% fat) and distilled water necessary to reach consistency 600 Brabender units (BU). Dough fermentation took $50 \mathrm{~min}$ at $32{ }^{\circ} \mathrm{C}$ and relative humidity $80 \%$, and the mass was split to $70 \mathrm{~g}$ pieces moulded by hand. Full baking sheet was returned into fermentation chamber for leavening taking $45 \mathrm{~min}$. Baking was carried out in laboratory baking oven preheated to $240{ }^{\circ} \mathrm{C}$ and steamed immediately after inserting a baking plate. Manufactured buns quality as volume and shape was described objectively after two hours cooling at room conditions.

\subsection{Statistical Analysis}

Data variance, caused by addition of the non-traditional flour and by three dosage levels of fonio flour, was explored by HSD test on level 95\% with the help of Statistica 7.1 software (Statsoft, USA). Relationships among recorded features and their contribution to composite bread quality were evaluated by principal component analysis (PCA). Data matrix comprised 21 representative features from 10 technological proofs conducted (of 35 ones in total), based on previous experiences [20, 21]. Contribution of features of flour technological quality to bread quality was estimated on base of statistical similarities (hierarchical cluster analysis in Euclidean space, standardized data, Complete clustering algorithm).

\section{Results and Discussion}

\subsection{Fonio Flour Effect on Analytical Characteristics}

Due to botanical affinity and similarity in proteins structure, neither $10 \%$ fonio flour did not affected Zeleny sedimentation value of WF control markedly; a decrease represent ca $10 \%$ (Table 2). Fonio flour did not demonstrate higher amylases activity than WF, Falling Number value of the control $400 \mathrm{~s}$ decreased about $5 \%$ only.

Table 2. Fonio flour effect on technology analytical features

\begin{tabular}{|c|c|c|c|}
\hline Sample & Fonio addition (\%) & Zeleny value (ml) & Falling number (s) \\
\hline WF & 0.0 & 32 & $400 \mathrm{a}$ \\
\hline $\mathrm{W} 2.5 \mathrm{~F}$ & 2.5 & 29 & 425 a \\
\hline W5F & 5.0 & 28 & 404 a \\
\hline W10F & 10.0 & 27 & 384 a \\
\hline Repeatability & & 1 & 25 \\
\hline
\end{tabular}

WF - wheat flour; W2.5F - wheat composite flour, blended from wheat and fonio flour in ratio 97.5:2.5 (w/w). a-b: means in column marked by the same letter are statistically similar $(\mathrm{P}=95 \%)$.

\subsection{Fonio Flour Effect on Non-fermented Dough Properties}

During dough preparation, water absorption was not influenced by constitution of tested flour blend (Figure 1). In addition, dough development time did not vary significantly, values range was $1.25-2.75$ min (data not shown). Differences between flour composites were observed in overmixing phase of the farinograph test - very good stability of WF control (12.00 min) fell stepwise up to $3.50 \mathrm{~min}$ for sample W10F (Figure 1). On the other hand, change in composite dough cohesiveness, expressed by dough softening degree, increases only twice from 30 to 60 Brabender unit (BU), i.e. less than could be expected. That phenomenon could be addressed to fonio fibre, which disrupted gluten skeleton in part, but was able to absorb water released from proteins. 


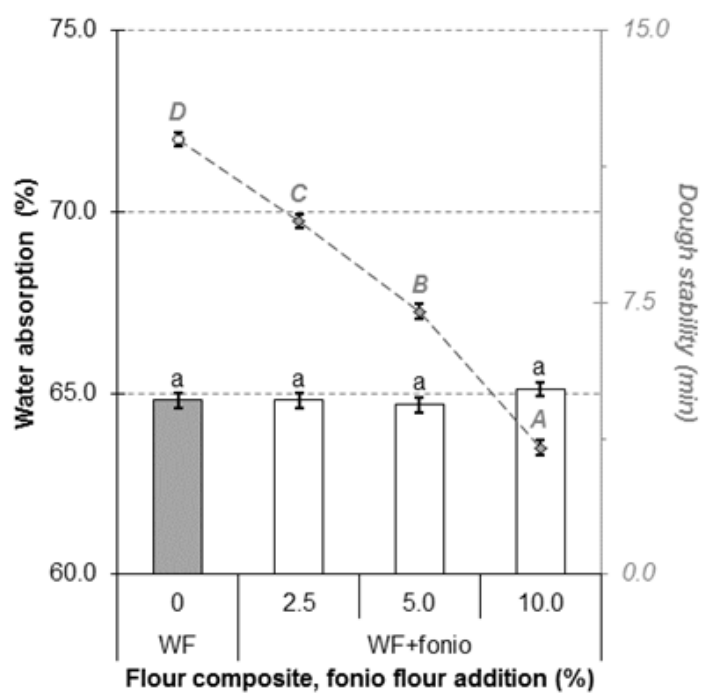

Figure 1. Fonio flour effect on farinograph characteristics. a, A-D - columns and dots, respectively, marked by the same letter are not statistically different $(\mathrm{P}=95 \%)$.

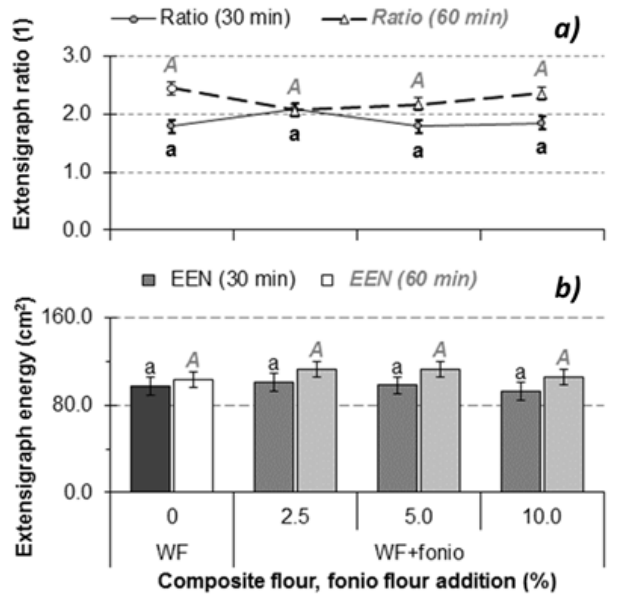

Figure 2. Fonio flour effect on extensigraph characteristics. a) elasticity-to-extensibility ratio, b) energy. a, A average values, determined after 30 and $60 \mathrm{~min}$ of dough resting, respectively, marked by the same letter, are not statistically different $(\mathrm{P}=95 \%)$.

Extensigraph parameters, elasticity-to-extensibility ratio and energy, were ambiguously dependent on composition of tested blends. Longer dough resting time elevated the values about $25 \%$ and $13 \%$ in average, respectively (Figure 2a, 2b). A partial improvement of dough handling properties caused 5\% addition of fonio, which supported dough elasticity in a small extent (data not shown).

\subsection{Fonio Flour Effect on Pasting Properties}

Non-traditional plant materials are usually characterised by higher dietary fibre content, and these polysaccharides have a hydrophilic nature. Wheat flour, used as control, was characterised by low amylases activity - its amylograph maximum 1040 BU (Figure 3) was estimated close to technical limit of the amylograph $(1000 \mathrm{BU})$. All three additions of fonio did not affect temperature of gelatinization beginning (WF 69.5, composites $69.0-71.0{ }^{\circ} \mathrm{C}$; Figure 3), but they increased maximal viscosity over the limit (actual values unevaluatable). Reversely, Ayo and Nkama [11] mentioned viscosity decrease from 2405 to $1460 \mathrm{BU}$ as ratio of fonio flour (acha grain one) increased from 0 to $100 \%$. Within the set 
of wheat-hemp and wheat-teff composite flour, control sample reached $400 \mathrm{BU} ; 20 \%$ dosage of mentioned alternative materials increased amylograph viscosity verifiably [15].

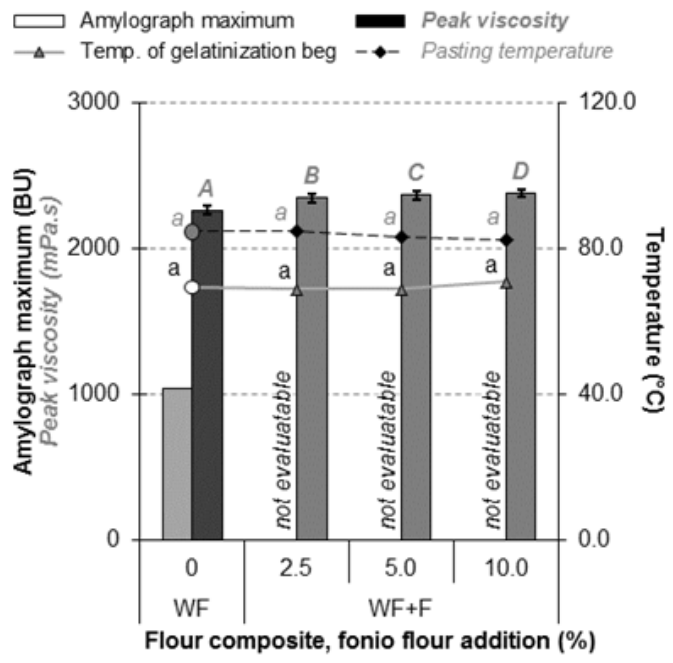

Figure 3. Fonio flour effect on amylograph and RVA pasting characteristics. not evaluatable - maximal amylograph viscosity overcame technical limit $1000 \mathrm{BU}$ of the apparatus. a, A-D - columns and dots, respectively, marked by the same letter are not statistically different $(\mathrm{P}=95 \%)$.

RVA readings confirmed the amylograph results - pasting temperatures were comparable between four tested samples. Maximal RVA viscosity (peak viscosity) was softly and positively dependent on fonio ratio in analysed flour composites. Overall increase was $118 \mathrm{mPa} \cdot \mathrm{s}$ only, equal to $5.2 \%$ of the control value.

\subsection{Fonio Flour Effect on Fermented Dough Behaviour}

Fermentation process, observed in three technological phases, was influenced by dough recipe modification positively. Fermentograph and maturograph times of reaching maximal volume were comparable through whole sample set (approx. $36 \mathrm{~min}$, data not shown). Between the control and flour composites, final dough volumes were comparable during the fermentograph test (Table 3); a significant increase, caused already by the lowest fonio flour addition, occurred in phases of dough proofing (maturograph test) and simulated baking in oil bath (OTG test). An accrual was counted at 20\% level in both mentioned cases (e.g. from 500 to 620 BU for maturograph dough resistance, Table 3). As could be presumed, higher fonio dosages did not disrupt gluten net skeleton and the volumes maintained comparable to ones of W2.5F composite.

Table 3. Influence of fonio flour on rheological behaviour of fermented dough

\begin{tabular}{lllllll}
\hline Proof & \multicolumn{2}{l}{ Fermentograph } & \multicolumn{2}{l}{ Maturograph } & \multicolumn{2}{l}{ Oven rise recorder } \\
Sample & Final dough volume $(\mathrm{FeU})$ & \multicolumn{2}{l}{ Dough resistance $(\mathrm{BU})$} & Volume rise (BU) \\
\hline WF & 72 & $\mathrm{a}$ & 500 & $\mathrm{a}$ & 170 & $\mathrm{a}$ \\
W2.5F & 66 & $\mathrm{a}$ & 620 & $\mathrm{~b}$ & 230 & $\mathrm{~b}$ \\
W5F & 69 & $\mathrm{a}$ & 630 & $\mathrm{~b}$ & 230 & $\mathrm{~b}$ \\
W10F & 71 & $\mathrm{a}$ & 620 & $\mathrm{~b}$ & 280 & $\mathrm{c}$ \\
Repeatability & 4.70 & & 3.50 & & 5.40 & \\
\hline
\end{tabular}

WF - wheat flour; W2.5F - wheat composite flour, blended from wheat and fonio flour in ratio 97.5:2.5 (w/w) FeU - fermentograph unit, BU - Brabender unit.

a-c: column means marked by the same letter are statistically similar $(\mathrm{P}=95 \%)$. 


\subsection{Fonio Flour Effect on Bread Quality}

In correspondence to higher maturograph dough resistance and OTG volume rise, specific volume of bread prepared from W2.5F was about $20 \%$ higher than the control (Figure 4). Bread variants from W5F and W10F reached volumes comparable to the control (repeatability $\pm 15 \mathrm{ml} / 100 \mathrm{~g}$ ). A partial decrease could be ascribed to longer proofing phase within the laboratory baking trial than optimal proofing times recorded during the maturograph test (45 min vs. $36 \mathrm{~min}$ in average; data not shown). Fonio as a cereal contains protein structures comparable to wheat, but its white variant acha is characterised by higher content of prolamin fraction than glutelin one [4]. Considering this finding, addition of $5 \%$ or $10 \%$ fonio flour likewise lowered a total amount of gluten in composite dough and worsened fermentation gases capture during longer dough proofing. Results published by Ayo and Nkama [11] were in correspondence to mentioned finding - increasing ratio of fonio flour in recipe lowered bread volume and worsened sensorial score significantly. Authors recommended recipe dosage of fonio flour up to $30 \%$. Also Igyor [12] found recipe ratios 85:15, 80:20, 75:25 of wheat-acha flour as applicable in praxis, which render baked products with quality comparable to wheat control.

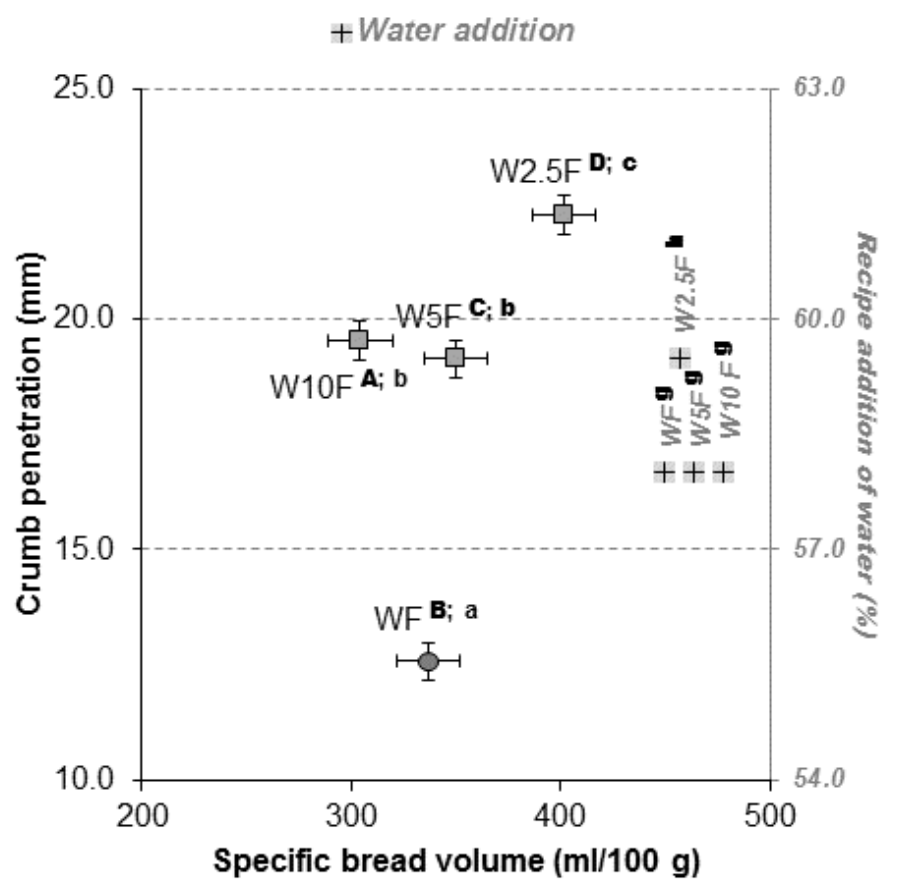

Figure 4. Fonio flour effect on baking trial results. a-c, A-D, g-h - average values of specific bread volume, crumb penetration and recipe addition of water, respectively, marked by the same letter are not statistically different.

\subsection{Multivariate Statistics}

Variance of 21 qualitative features was explained from $85 \%$ by the first two principal components (PC), from $49 \%$ and $36 \%$ by PC1 and PC2 in average, respectively (Table 4). The third PC had a substantial role for farinograph water absorption ( $42 \%$ of data scatter), temperature of gelatinization beginning (24\%), bread shape $(71 \%)$ and sensory profile $(31 \%)$. Positive semi-axis PC1 could be interpreted as protein technological quality (Zeleny test, extensigraph parameters), while the negative semi-axis describes flour pasting and fermented dough behaviour during baking (OTG test). For the PC2, its negative semi-axis has the prior importance - it comprised 16 qualitative parameters from 21. Due to these almost negative correlations among the $\mathrm{PC}$ and quality features (Table 4), the highest baking potential of composite flour could be identified in the III. and IV. quadrant of the plot (Figure 5). 
Table 4. Portion (\%) of explaned variability by the first two principal components (PC)

\begin{tabular}{llllll}
\hline Proof & Feature & Abbrev. & PC1 & PC2 & Total \\
\hline ANA & Zeleny value & ZT & $76^{* * *}$ & 12 & 88 \\
& Falling number & FN & $40^{* *}$ & $59^{* * *}$ & 99 \\
FAR & Water absorption & WAF & $56^{* * *}$ & 2 & 58 \\
& Dough stability & Sfar & $98^{* * *}$ & 0 & 98 \\
EXT & Extensigraph ratio & ERA 30 & 1 & $85^{* *}$ & 86 \\
& Extensigraph energy & EEN 30 & $57^{* * *}$ & $38^{* *}$ & 95 \\
AMY & Temp. of gelatinization beginning & Tbeg & $62^{* * *}$ & 14 & 76 \\
& Viscosity maximum & AMA & $43^{* *}$ & $45^{* * *}$ & 88 \\
RVA & Pasting temperature & PTe & $83^{* * *}$ & 6 & 89 \\
& Peak viscosity & PV & $66^{* * *}$ & $22^{*}$ & 88 \\
FER & Fermentation time & Tfer & $86^{* * *}$ & 5 & 92 \\
& Final dough volume & FDV & 2 & $95^{* * *}$ & 97 \\
MAT & Proofing time & Tmat & $82^{* * *}$ & 4 & 86 \\
& Dough resistance & DRE & $41^{*}$ & $42^{* *}$ & 82 \\
OTG & Sample volume & V11 & $52^{* * *}$ & $31^{* *}$ & 83 \\
& Bread volume increase & V22-V0 & $88^{* * *}$ & 12 & 100 \\
BAT & Recipe addition of water & RAW & 8 & $84^{* * *}$ & 93 \\
& Specific bread volume & SBV & $34^{* *}$ & $65^{* * *}$ & 99 \\
& Bread shape & BRS & 2 & $26^{*}$ & 29 \\
& Crumb penetration & PEN & $21^{*}$ & $77^{* * *}$ & 97 \\
& Bread sensory profile & SEN & $29^{*}$ & $40^{* *}$ & 69 \\
& Average & & 49 & 36 & 85 \\
\hline
\end{tabular}

Proofs: ANA - analytics; Non-fermented dough rheology: FAR - Farinograph, EXT - Extensigraph; Slurry rheology: AMY - Amylograph, RVA - Rapid Visco Analyser; Fermented dough rheology: FER - Fermentograph, MAT - Maturograph, OTG - Oven rise recorder; BAT - Baking trial. $*, * *, * * *$ - correlation between $\mathrm{PC} 1$ or $\mathrm{PC} 2$ and the qualitative feature significant on $\mathrm{P}=95 \%, 99 \%$ and $99.9 \%$, respectively.

Underlined italic value signifies a negative correlation.

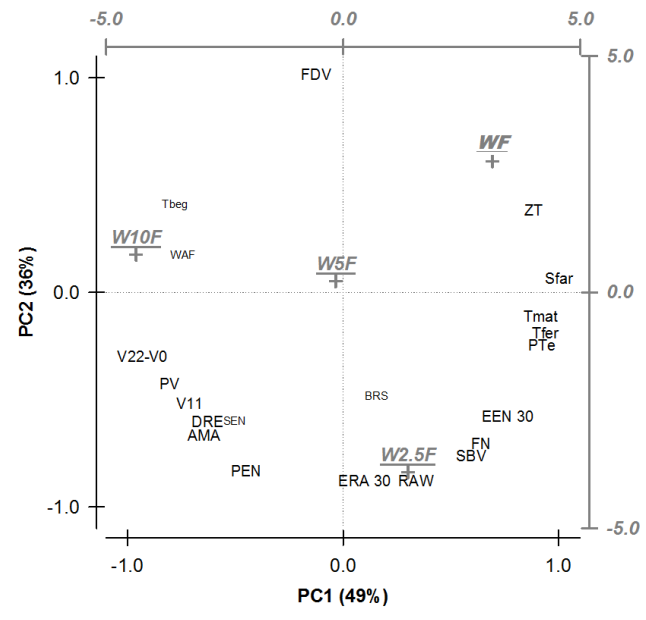

Figure 5. Biplot of variables (flour quality features) and cases (wheat flour and flour composite samples). PC1, PC2 - the first and the second principal component. Samples marked with plus sign and codes: WF - wheat flour, W2.5F, W5F, W10F - wheat flour composites containing $2.5 \%, 5.0 \%$ and $10.0 \%$ of fonio one, respectively. Abbreviations of qualitative features are summarized in Table 4.

Positions of tested samples mainly to protein quality and baking trial results - wheat control reached the highest value in Zeleny test and the longest stability of dough during kneading. In wheat flour 
composites, fonio flour did not affect WF technological quality seriously due to similar protein structures (Jideani et al., 1994). For composite W2.5F, higher Falling Number, extensigraph ratio and specific bread volume dominate over the other parameters. Position of W10F flour composite, it is based on lower Zeleny test value, very short farinograph stability but better OTG proof results compared to control. In this regard, technological quality of W5F sample seemed to have technological quality applicable in praxis without substantial operation changes (the closest sample to WF control).

In Table 5, contributions of each of measured characteristics to bread quality are summarised. An extraordinary role could be considered for extensigraph ratio and recipe addition of water because of their statistical similarities to specific bread volume, bread shape, crumb penetration and sensory profile higher than 50\%. For bread quality prediction, together six measured parameters should be used Falling Number or amylograph maximal viscosity, extensigraph energy after 30 min of dough resting, maturograph dough resistance, OTG volume of sample (V11) and recipe addition of water.

Table 5. Contribution of dough features to bread quality (statistical similarities)

\begin{tabular}{llllllllll}
\hline Feature & ZT & FN & WAF & Sfar & ERA 30 & EEN 30 & Tbeg & AMA \\
\hline SBV & 37 & 97 & 10 & 52 & 66 & 86 & 5 & 36 \\
BRS & 38 & 45 & 43 & 38 & 69 & 38 & 33 & 27 \\
PEN & 6 & 45 & 33 & 13 & & 61 & 38 & 27 & 83 \\
SEN & 13 & 32 & 60 & 14 & & 63 & 24 & 48 & 54 \\
& & & & & & & & & \\
Feature & PTe & PV & Tfer & FDV & Tmat & DRE & V11 & V22-V0 & RAW \\
SBV & 61 & 27 & 61 & 3 & 63 & 36 & 29 & 20 & 75 \\
BRS & 52 & 23 & 50 & 17 & 26 & 25 & 51 & 30 & 64 \\
PEN & 21 & 71 & 20 & 4 & 23 & 80 & 65 & 63 & 57 \\
SEN & 24 & 52 & 23 & 15 & 11 & 51 & 88 & 62 & 54 \\
Statistical similarity: & $>50 \%$, & $>75 \%$. & & & & & & \\
\hline
\end{tabular}

For the feature abbreviations, see Table 4.

\section{Conclusions}

Testing fonio flour composites in form of flour suspension, non-fermented and fermented dough, rheological proofs shown prevailing positive effect of fonio flour in gradually increasing dosages $2.5 \%, 5.0$ and $10.0 \%$. During dough proofing phase especially, fonio flour supported dough volumes increase, resulting into specific bread volumes comparable to wheat control at least. Dosage of $2.5 \%$ of fonio influenced dough machinability and bread quality most positively - specific bread volume increased from 337 to $402 \mathrm{ml} / 100 \mathrm{~g}$ and crumb softness as crumb penetration rose from 12.6 to $22.3 \mathrm{~mm}$. Based on results of principal components analysis, dosage of $5 \%$ of fonio flour could be recommended. Further, quality of composite bread could be predicted according to pasting behaviour (amylograph maximum), viscoelastic properties of non-fermented dough (extensigraph energy) and dough volume in phase of proofing (maturograph resistance).

The novelty of present article lies on complex exploration of technological impact of fonio flour addition on rheological properties of wheat flour and quality of wheat bread. In terms of changing geopolitical situation in the Europe, fonio should be one of non-traditional plant raw materials, which is common in diet of refugees. Moreover, positive impact of fonio flour on consumer's quality of leavened bread may give a preference to its practical applications in food industry.

\section{References}

1. J. A. Ayo and I. Nkama, "Acha (Digitaria exilis) in West Africa". International Journal of Food and Agriculture, vol. 1, pp. 129-144, 2006.

2. M. N. Emmambux and J. R. N. Taylor, "Morphology, physical, chemical, and functional properties of starches from cereals, legumes, and tubers cultivated in Africa: A review". Starch/Stärke, vol. 65, pp. 715-729, 2013. 
3. V. A. Jideani, A. R. Salami and I.A. Jideani, "Effect of Irish potato starch, yeast and sprouted soybean flour on the quality of acha bread". British Food Journal, vol. 110, pp. 271-282, 2008.

4. R. Coda, R. Di Cagno, M. O. Edema, et al., "Exploitation of Acha (Digitaria exilis) and Iburu (Digitaria iburua) flours: Chemical characterization and their use for sourdough fermentation". Food Microbiology, vol. 27, pp. 1043-1050, 2010.

5. I. A. Jideani, "Traditional and possible technological uses of Digitaria exilis (acha) and Digitaria iburua (iburu): a review". Plant Foods for Human Nutrition, vol. 54, pp. 363-374, 1999.

6. Ayo J.A., \& Nkama, I. (2003). Effect of acha (Digitaria exilis Staph.) grain flours on the physical and sensory quality of biscuit. Nutrition \& Food Science, 33, 125-130.

7. I. A. Jideani and E. R. Ibrahim, "Some food potential of acha (Digitaria exilis) and iburu (D. iburua) grains emanating from current research, 2005. Proceedings. 29th annual Nigerian Institute of Food Science and Technology conference/AGM, Nigeria, 2005, pp. 60-61.

8. V. A. Jideani, R. Alamu and I.A. Jideani, "Preliminary study into the production of non-wheat bread from acha (Digitaria exilis)". Nutrition and Food Science, vol. 37, pp. 434-441, 2007.

9. J. A. Ayo, I. Nkama, U. S. Haruna, et al., "Effect of dough improvers on the physical and sensory quality of acha (Digitaria exilis) flour bread". Nigerian Food Journal, vol. 26, pp. 102-110, 2008

10.I.A. Jideani and J. O. Akingbala, "Some physiochemical properties of acha (Digitaria exilis Stapf.) and Iburu (Digitaria iburua Stapf.) grains. Journal of the Science of Food and Agriculture, vol. 63, pp. 369-371, 1993.

11.M. Hrušková, I.Švec and I. Jurinová, "Chemometrics of wheat composites with hemp, teff, and chia flour: comparison of rheological features". International Journal of Food Science, Article ID 968020, 6, 2013. http://dx.doi.org/10.1155/2013/968020.

12.J. A. Ayo and I. Nkama, I. (2004). Effect of Acha (Digitaria exilis) grain flour on the physico-chemical and sensory properties of bread. International Journal of Food Properties, 7, 561-569.

13.M. A. Igyor, "Substitution of wheat flour with "acha" (Digitaria exilis) for bread making". Botswana Journal of Technology, vol. 14, pp. 51-57, 2005.

14.I. A. Jideani, R. K. Owusu and H. G. Muller, "Proteins of acha (Digitaria exilis Stapf.): Solubility fractionation, gel filtration, and, electrophoresis of protein fractions". Food Chemistry, vol. 51, pp. 51-59, 1994.

15.M. O. Edema, M. N. Emmambux and J. R. N. Taylor, "Improvement of fonio dough properties through starch modification by sourdough fermentation". Starch/Stärke, vol. 65, pp. 730-737, 2013.

16.K. H. McWatters, J. B. Ouedraogo, A. V. A. Resurreccion et al, "Physical and sensory characteristics of sugar cookies containing mixtures of wheat, fonio (Digitaria exilis) and cowpea (Vigna unguiculata) flours". International Journal of Food Science and Technology, vol. 38, pp. 403-410, 2003.

17.A. Olapade and O. B. Oluwole, "Bread making potential of composite flour of wheat-acha (Digitaria exilis Staph.) enriched with cowpea (Vigna unguiculata L. Walp.) flour". Nigerian Food Journal, vol. 31, pp. 6-12, 2013.

18.I. Švec, and M. Hrušková, "Flour, dough, and bread properties of wheat/barley/hemp composite flour as affected by the barley and hemp content". Cereal Technology, vol. 3, pp. 108-117, 2014.

19.M. Hrušková, I. Švec and O. Jirsa, "Correlation between milling and baking parameters of wheat varieties", Journal of Food Engineering, vol. 77, pp. 439-444, 2006.

20.I. Švec, and M. Hrušková, "Evaluation of wheat bread features". Journal of Food Engineering, vol. 99, pp. 505510, 2010.

21.M. Hrušková, I. Švec, "Vztahy jakostních znaků potravinářské pšenice, pšeničné mouky, těsta a pečiva". ("Relationships among quality characteristics of food wheat, wheat flour, dough and bread"). Mlynářská ročenka 2009, pp. 152-182, 2009 (In Czech).

22.I. Švec, and M. Hrušková, "Modelling of wheat, flour and bread quality parameters". Scientia Agriculturae Bohemica, vol. 40, pp. 58-66, 2009. 